\title{
Artikel
}

\section{Naar een Gedragscode Afhandeling Beroepsziekteclaims?}

\section{Een verkorte weergave van de bevindingen van de eerste fase van het project Gedragscode Afhandeling Beroepsziekteclaims}

Mr. M. de Groot*

\section{Inleiding}

De afhandeling van beroepsziekteclaims wordt in de praktijk als problematisch ervaren. De afwikkeling duurt lang, kost veel en wordt als moeizaam beleefd. Ondanks eerdere onderzoeken en initiatieven zijn tot op heden geen concrete stappen gezet in de verbetering van de afhandeling van beroepsziekteclaims. ${ }^{1}$ Om de afwikkeling te verbeteren, is op initiatief van De Letselschade Raad in januari 2018 het project Gedragscode Afhandeling Beroepsziekteclaims (project GAB) gestart. Deze bijdrage beoogt een korte weergave te geven van de bevindingen van de eerste fase van dit project, waarin een inventariserend onderzoek is verricht naar de ervaren problemen bij de afhandeling van beroepsziekteclaims en de kansen voor een gedragscode als oplossingsrichting. ${ }^{2}$

* Mr. M. de Groot is als wetenschappelijk docent verbonden aan de sectie Burgerlijk recht van de Erasmus School of Law en was secretarisonderzoeker van de eerste fase het project Gedragscode Afhandeling Beroepsziekteclaims.

1. Het blijft bij enkele incidentele regelingen. Zie voor Chroom-6 (www rijksoverheid.nl/onderwerpen/chroomverf/regeling-uitkering-chroom-6 -defensie) en OPS (www.rijksoverheid.nl/actueel/nieuws/2019/03/29/ regeling-eenmalige-financiele-tegemoetkoming-slachtoffers\%E2\%80\%98schildersziekte\%E2\%80\%99).

2. Zie voor het volledige onderzoeksverslag M. de Groot \& S.D. Lindenbergh, Naar een Gedragscode Afhandeling Beroepsziekteclaims? Een inventarisatie van problemen bij afwikkeling van beroepsziekteclaims
In het vervolg van deze bijdrage zal eerst nader worden ingegaan op het project $\mathrm{GAB}$ en de eerste fase daarvan. Vervolgens zullen op hoofdlijnen de bevindingen van deze eerste fase worden besproken. Tot slot volgt een korte afronding waarin onder andere de vervolgfase van het project wordt aangestipt.

\section{Het project $G A B$, de eerste fase}

Het project GAB heeft tot doel om, onder auspiciën van De Letselschade Raad, in overleg en samenwerking met relevante partijen uit de letselschadebranche te komen tot een gedragscode waarin afspraken kunnen worden neergelegd over de wijze waarop een beroepsziekteclaim wordt afgehandeld. Het project GAB wordt gefaciliteerd door het Ministerie van Sociale Zaken en Werkgelegenheid en kent twee fases: de inventariserende fase, waarin de kansen voor een gedragscode op dit punt worden verkend, gevolgd door een creërende fase, waarin door een breed samengestelde werkgroep, onder aansturing van een stuurgroep, zal worden getracht een gedragscode op te stellen.

en van kansen voor een gedragscode als oplossingsrichting, november 2018 (online): https://deletselschaderaad.nl/wp-content/uploads/ Rapport-Gedragscode-Afhandeling-Beroepsziekteclaims-definitief-versie -publicatie_.pdf. 
De inventariserende fase is inmiddels achter de rug en heeft geleid tot een rapport dat zowel specifieke inzichten omvat in de knelpunten die in de branche worden gesignaleerd als oplossingsrichtingen waaraan een gedragscode zou kunnen bijdragen. Hiervoor zijn de onderzoekers door middel van diepte-interviews en consultatierondes in gesprek gegaan met zo veel mogelijk verschillende professioneel betrokken partijen bij de afhandeling van beroepsziekteclaims. Gesproken is met werkgeversvertegenwoordigers, verzekeraars, belangenbehartigers, vakbondsvertegenwoordigers, brancheverenigingen, medisch adviseurs, deskundigen op het gebied van de blootstelling en de causaliteit, rechters, wetenschappers en overige betrokkenen. De respondenten zijn bevraagd naar de problemen zoals die in de praktijk worden ervaren, de mogelijke oplossingsrichtingen daarvoor en de wijze waarop volgens hen een gedragscode aan de verbetering van de afhandeling van beroepsziekteclaims zou kunnen bijdragen. Op die manier is in kaart gebracht of voldoende aanknopingspunten bestaan om te gaan werken aan de totstandkoming van een gedragscode.

\section{Bevindingen op hoofdlijnen}

\subsection{Ervaren knelpunten}

Als antwoord op de vraag naar de ervaren problemen zijn veel uiteenlopende knelpunten genoemd. Uit de hoeveelheid en de aard van de genoemde knelpunten blijkt dat de afhandeling van beroepsziekteclaims in de praktijk als (zeer) problematisch wordt ervaren; de afhandeling duurt (te) lang, kost (te) veel en is (te) belastend voor betrokken partijen:

'Tien jaar is niks eigenlijk.' 3

'De problematiek ten aanzien van beroepsziekten is juridisch zo ingewikkeld en dus zo duur, (...) dat de werknemer in een bijna onmogelijke situatie zit om daarover te procederen.' ${ }^{4}$

'En dan hebben we het nog niet eens gehad over wat misschien nog wel een groter probleem is dan de financiële belasting en dat is natuurlijk het anti-therapeutische effect van zo een traject. Je plaatst mensen in een heel akelig rollenspel waarin ze elkaars vijanden zijn in plaats van dat ze samenwerken om de schade te beperken en zich te focussen op herstel en re-integratie.'

Als oorzaken van de problematiek op het gebied van beroepsziekteclaims zijn veel verschillende knelpunten aangevoerd, waaronder de moeilijk objectiveerbare klachten en diffuse ziektebeelden, het moeten achterhalen van relevante feiten terug in de tijd, de vertrouwens- relatie tussen werkgever en werknemer, het multicausale karakter van veel beroepsziekten, de opeenstapeling van deskundigen, de jurisprudentie van de Hoge Raad en de vage arbonormen.

De voornaamste problemen lijken zich voor te doen bij drie stappen in de afhandeling van een beroepsziekteclaim: het vaststellen van de blootstelling aan voor de gezondheid risicovolle omstandigheden, het vaststellen van de causaliteit en het inschakelen van (externe) deskundigen. Op de ervaren problemen bij deze stappen van afhandeling wordt in het vervolg van deze bijdrage nader ingegaan.

\subsubsection{Vaststelling blootstelling}

De vaststelling van de blootstelling aan voor de gezondheid risicovolle omstandigheden, en in het bijzonder de mate van blootstelling, is door een groot deel van de respondenten aangemerkt als een belangrijk knelpunt, waarover tijdens de afhandeling veel discussie kan bestaan:

'De blootstelling sec is meestal niet echt een discussie, alleen de mate van blootstelling dat is lastig.' 6

Als oorzaak van deze problematiek op het gebied van het bewijs van de blootstelling is door velen het tijdverloop genoemd dat zich op verschillende wijzen bij beroepsziekteclaims kan voordoen. Allereerst is in dit kader gewezen op het sluipende ontstaansmechanisme dat veel beroepsziekten kennen. Anders dan bij een bedrijfsongeval kent een beroepsziekte namelijk vaak geen duidelijk ontstaansmoment, maar een periode van blootstelling waarin een werknemer steeds meer klachten ervaart en (vaak) steeds vaker verzuimt, totdat hij definitief uitvalt. Ten tweede is als oorzaak van tijdverloop de (lange) latentietijden van verschillende beroepsziekten genoemd. Hiermee wordt gedoeld op de periode die zich kan voordoen tussen de blootstelling aan risicovolle omstandigheden en het openbaren van de gezondheidsklachten. Ten derde is de vertrouwensrelatie die zich voordoet tussen de werkgever en de werknemer als factor genoemd die van invloed kan zijn op het tijdverloop bij beroepsziekteclaims. Aangevoerd is dat werknemers vanwege angst op baanverlies en/of loyaliteit jegens de werkgever in veel gevallen pas een beroepsziekteclaim indienen op het moment dat hun arbeidsovereenkomst is ontbonden of dat daarop het vooruitzicht bestaat:

'En je hebt ook altijd uitzonderingen die zoiets zeggen van "de relatie is toch al slecht het makt me helemaal niks meer uit. Ga je gang maar”. Maar de meesten die komen pas als ze al ontslagen zijn.'7

Als gevolg van het sluipende ontstaansmechanisme, de latentietijden en de vertrouwensrelatie tussen de werkgever en de werknemer moet voor het vaststellen van de 
blootstelling bij een beroepsziekteclaim veelal worden gekeken naar een bepaalde periode terug in de tijd, die al dan niet bij verschillende werkgevers heeft plaatsgevonden. Dit tijdverloop makt volgens een groot deel van de respondenten het aantonen van de blootstelling complex en soms zelfs (gedeeltelijk) onmogelijk, aangezien relevante informatie hierdoor moeilijk of zelfs niet meer te achterhalen is:

'Daarmee houdt verband dat bijvoorbeeld werkplekonderzoek bij verzekerde na verloop van zoveel tijd niet meer goed mogelijk is, omdat die situatie er bijvoorbeeld helemaal niet meer is.'

Behalve tijdverloop zijn ook andere factoren aangevoerd die het achterhalen van de blootstelling problematisch maken, waaronder een gebrek aan openheid van informatie door betrokken partijen. In dit verband is, in het bijzonder door respondenten die vanuit werknemerskant bij de afhandeling van beroepsziekteclaims zijn betrokken, aangevoerd dat door de werknemer of zijn belangenbehartiger in veel gevallen geen onderzoek op de werkplek wordt of kan worden uitgevoerd. Als oorzaak hiervan is onder andere genoemd dat de werkgever hiervoor veelal geen toestemming verleent. Eveneens is aangevoerd dat voor de onderbouwing van de blootstelling relevante stukken, zoals een personeelsdossier of een risico-inventarisatie, niet altijd door werkgevers worden verstrekt. Ook komt het voor dat werkgevers dergelijke relevante stukken geheel niet of van onvoldoende kwaliteit hebben opgesteld:

'Als we die [de risico-inventarisatie] al krijgen dan is die vaak ook nog onzorgvuldig.'

Opvallend is dat in het bijzonder door respondenten die aan de kant van de werkgever of zijn verzekeraar betrokken zijn bij de afhandeling van beroepsziekteclaims, is aangevoerd dat bij aanvang van de minnelijke afhandeling de blootstelling vanuit werknemerszijde veelal enkel wordt gebaseerd op het verhaal van de werknemer. Ook is opgemerkt dat informatie, onder andere over een eventuele relevante blootstelling bij een andere werkgever of buiten het werk, niet altijd wordt verzameld en/of gedeeld.

\subsubsection{Vaststelling causaliteit}

De vaststelling van het causaal verband is door alle respondenten aangemerkt als (zeer) complex en vormt volgens veel respondenten één van de voornaamste knelpunten, zo al niet het voornaamste knelpunt, van de afhandeling van beroepsziekteclaims:

'Dat is bijna zo een beetje de moeilijkste vraag die je op de LSA-opleiding kunt stellen, over causaliteit bij beroepsziekten.' 10
Als oorzaken van de problematiek rondom het causaal verband zijn vooral tijdverloop en multicausaliteit genoemd. Met betrekking tot het tijdverloop is in dit kader in het bijzonder gewezen op het sluipende ontstaansmechanisme dat veel beroepsziekten kennen. Als gevolg van dit mechanisme is een ontstaansmoment niet altijd aan te wijzen, maar kan ook het verband met een mogelijke oorzaak weinig evident zijn. Daarnaast kunnen aandoeningen verschillende alternatieve of samenwerkende oorzaken hebben (multicausaliteit), hetgeen volgens een groot deel van de respondenten het aantonen van het causaal verband (des te meer) complex maakt:

'Maar bij burn-out is dat natuurlijk een heel goed voorbeeld. Dat kan zowel van het werk komen als van een andere oorzaak of van allebei.'11

'Ja, iemand heeft een leverziekte, ja, dat kan door een chemische stof komen, maar het kan ook zijn dat hij alcohol gedronken heeft in zijn privé.' 12

\subsubsection{Inschakelen externe deskundigen}

Vanwege de complexiteit van het vaststellen van de blootstelling en de causaliteit dient in veel gevallen voor de beoordeling hiervan, al dan niet gezamenlijk, een deskundige te worden ingeschakeld op het gebied van de blootstelling respectievelijk de causaliteit. Ook worden tijdens de afhandeling van beroepsziekteclaims deskundigen ingeschakeld op het gebied van de aard en de omvang van de schade. Behalve dat het inschakelen van dergelijke externe deskundigen tijd en geld kost, doen zich hierbij volgens respondenten ook andere knelpunten voor. $Z_{o}$ is aangevoerd dat veelal discussie bestaat over de keuze van de expertise, de persoon van de deskundige en/of de voor te leggen vraagstelling:

'A: Dus dat deskundigenwerkveld dat is een groot probleem. Zowel voor wat betreft de keuze van de discipline als voor wat betreft de keuze van de persoon.

B: Daarop aansluitend en dan vervolgens nog de discussie over de vraagstelling. Dat is ook vervolgens weer een nieuw discussiepunt.

A: Dus daar gaat al heel veel tijd mee heen.' ${ }^{13}$

Tevens is de inhoud van een deskundigenbericht aangemerkt als bron van discussie bij de afhandeling van beroepsziekteclaims. In dit verband is aangevoerd dat de inhoud van een deskundigenbericht over de causaliteit, de blootstelling en/of de aard en de omvang van de schade veelal nog verscheidene onzekerheden bevat. Vermoedelijk omdat onzekerheden inherent zijn aan de materie die zich bij beroepsziekteclaims voordoet:

'En hier [bij beroepsziektezaken] lijkt op veel meer vlakken weer onzekerheid te ontstaan nadat deskun- 
digen hebben bericht. Dus dat is niet een soort valbijl of een soort salomonsoordeel waar je mee verder kan.' ${ }^{14}$

Volgens meerdere respondenten worden deze (inherente) onzekerheden in een deskundigenbericht door partijen aangegrepen om de uitkomst daarvan of de juridische waarde die daaraan door een partij wordt toegekend, in twijfel te trekken. Daarnaast speelt volgens een respondent ook het model van het aansprakelijkheidsrecht, waarin twee partijen tegenover elkaar staan die moeten stellen, verweren en bewijzen, een rol bij de discussie over de uitkomst van een deskundigenbericht:

\begin{abstract}
'Maar wat juristen natuurlijk wel leren en waar ze toe geneigd zijn, is dat als er een theoretische mogelijkheid is dat het niet $a$ is maar $b$, dat ze in het kader van het adversariële model dan toch gewoon, als de wederpartij roept het is a, dan nee hoor: het is b. En voordat je het weet ben je dan weer vijf brieven en een hoop geld en een hoop ellende verder. ${ }^{15}$
\end{abstract}

De onzekerheden die zich kunnen voordoen in de inhoud van een deskundigenbericht en het tweepartijenmodel van het aansprakelijkheidsrecht lijken ook een rol te spelen in de opeenstapeling van externe deskundigen, die zich volgens respondenten voordoet bij veel beroepsziekteclaims.

'Partijen hebben altijd het recht, en dat is het recht dat je ze ook nooit kunt ontzeggen in het model van het civiele procesrecht, om nog eens een eigen deskundige te gaan raadplegen of het allemaal wel klopt zo. Dus voordat je het weet ben je zo drie, vier deskundigen verder. En ja, het is die combinatie van de aard van de problematiek en het adversariële model, dat vergroot het allemaal nog eens heel erg uit. Die maakt dat het zo zwaar wordt.' 16

Aangevoerd is dat in een beroepsziektezaak al snel negen deskundigen worden geraadpleegd, namelijk door zowel beide partijen als de rechter één op het gebied van de blootstelling, één op het gebied van de causaliteit en één op het gebied van de aard en omvang van de schade. Deze opeenstapeling van deskundigen wordt door diverse respondenten als problematisch ervaren uit een oogpunt van tijd en geld.

\subsection{Gedragscode als oplossingsrichting?}

Gedurende het onderzoek is gebleken dat alle respondenten het van belang achten dat een oplossing wordt gevonden voor de ervaren knelpunten. Door respondenten zijn verschillende oplossingsrichtingen aangedragen, waaronder oplossingen binnen en buiten het aansprakelijkheidsrecht. Een gedragscode is door het overgrote deel van de respondenten genoemd als een oplossingsrichting voor de problematiek op het gebied van

14. Interview 9.

15. Interview 17

16. Interview 17. beroepsziekteclaims. De rol die respondenten voor een gedragscode zien weggelegd, verschilt echter enigszins. Zo is een gedragscode aangemerkt als de enige mogelijke oplossing van dit moment, maar ook als een 'second-best oplossing', als 'niet de oplossing' of als een eerste stap naar verbetering van de afhandeling en/of naar de uiteindelijke oplossing. Slechts een enkeling ziet in een gedragscode in het geheel geen oplossing.

\subsubsection{Kansen voor een gedragscode}

Door respondenten zijn verschillende suggesties gedaan voor de inhoud van een gedragscode, waaronder:

- het opstellen van een stappenplan waarin staat omschreven op welke wijze een beroepsziekteclaim moet worden afgehandeld;

- het opnemen van termijnen waarbinnen partijen dienen te reageren;

- het stroomlijnen van het vaststellen van de relevante feiten;

- het stroomlijnen van het inschakelen van (externe) deskundigen;

- het maken van afspraken over het vaststellen van de schadeomvang;

- het maken van afspraken over de kosten van de afhandeling;

- het maken van afspraken over het gebruik van mediation in een zo vroeg mogelijk stadium van de afhandeling.

In deze bijdrage worden enkel de suggesties nader uitgelicht die betrekking hebben op het stroomlijnen van het vaststellen van de relevante feiten, het stroomlijnen van het inschakelen van deskundigen en het vaststellen van de schadeomvang.

Ten behoeve van het stroomlijnen van de feitenvaststelling is onder andere geopperd 'een soort protocol' of 'een stappenplan' op te stellen, waarin afspraken worden neergelegd over de wijze waarop de relevante feiten, en in het bijzonder de blootstelling, in kaart dienen te worden gebracht:

'Je moet eens beginnen met een goede procedure. Dat je aangeeft van als er een claim komt voor beroepsziekten dan gaan we eerst beginnen, een stappenplan, die expositie goed in kaart te brengen bij deze cliënt, en niet [enkel] in het algemeen. We gaan ook kijken naar blootstelling buiten het werk. We gaan kijken naar individuele factoren. En met dat verhaal hebben we een compleet beeld en dat kunnen we aanleveren. Ik denk dat dat stap één is. Als je die procedure hebt, dat scheelt al een boel.'

Eveneens is voorgesteld dat in de gedragscode wordt opgenomen dat partijen vanaf het begin van het minnelijke traject openheid van informatie moeten bieden. Ook is als suggestie aangedragen dat partijen in een vroeg stadium gezamenlijk onderzoek doen naar de blootstelling: 
'Ik zou willen voorstellen in de [gedrags]code op te nemen aan de werkgever: er komen twee mensen, één voor jou en één namens ons, om eens te kijken hoe een en ander loopt van 9 tot 5. Daarna samen naar degene gaan die de claim indient. Die doet ook zijn verhaal van 9 tot 5 en dan kijk je naar de verschillen daarin.'

Ten aanzien van het stroomlijnen van het inschakelen van deskundigen is onder andere geopperd dat in de gedragscode wordt opgenomen dat partijen in het minnelijke traject externe deskundigen, en in het bijzonder een (medisch) deskundige op het gebied van de causaliteit, gezamenlijk inschakelen en diens oordeel in beginsel als maatgevend beschouwen:

'Nou, wat ik de moeilijkheid vind en wat ik ook een beetje beschreven heb, is dat beroepsziekten heel divers zijn en dat lijkt mij moeilijk om allemaal in één gedragscode precies te vatten, maar stel dat dat zou kunnen, dan zou je dus in die gedragscode hebben enerzijds van op welke wijzen vergaar je je informatie. (...) Vervolgens stel je een gezamenlijke vraag aan een deskundige van in de zin van nou, wat is de kans dat betrokkene een beroepsziekte heeft die is opgelopen door het werk? En dat oordeel accepteren we dan.'

Tevens is voorgesteld dat een vraagstelling wordt opgesteld die standaard in beroepsziektezaken aan externe deskundigen moet worden voorgelegd. Ook is geopperd dat een pool of lijst van onafhankelijke deskundigen wordt opgesteld waaruit kan worden gekozen als tijdens de minnelijke afhandeling of de gerechtelijke procedure een deskundige moet worden ingeschakeld.

In het kader van het vaststellen van de schadeomvang is in het bijzonder voorgesteld dat tijdens de afhandeling van een beroepsziektezaak de discussie over de schadeomvang naar voren wordt gehaald. In die zin, dat in de gedragscode moet worden opgenomen dat de (belangenbehartiger van de) werknemer reeds bij de aanvang van het minnelijke traject inzicht moet geven in het schadebedrag dat de werkgever bij volledige aansprakelijkheid zou moeten vergoeden.

\subsubsection{Winstpunten}

Aan de hand van bovenstaande suggesties kan een gedragscode volgens respondenten (onder andere) verbetering brengen in de drie overkoepelende problemen van beroepsziekteclaims: de tijdsduur, de kosten en de belasting:

'Een gedragscode kan dus de wijze waarop we in het veld met elkaar omgaan behelpen en dat leidt, zoals de ervaring leert, wel tot wat tijdswinst, omdat je niet vier keer gaat zitten schrijven naar elkaar met tussenpozen van vier weken. Maar je belt op of je ontmoet elkaar. Dat levert altijd versnelling op. ${ }^{17}$
'Ik denk dat je daar [het sneller afwikkelen van beroepsziekteclaims] heel veel psychische klachten mee gaat verminderen. Het brengt mensen ook, hebben rust, dan kunnen ze het ook afsluiten daarna. Zolang de zaak loopt, kun je het niet afsluiten.' ${ }^{18}$

'Kijk, en het voordeel is ook, als het niet zo lang duurt, kunnen mensen het hoofdstuk ook weer afsluiten en dan kunnen ze ook weer verder gaan [werken] en dan is de schade ook korter. (...) Maar eigenlijk zou je kunnen zeggen: zolang de zaak nog doorloopt, heb je er geen belang bij om weer werk te krijgen, want dan is die schade gewoon verdampt.' ${ }^{19}$

Niet alleen de gedragscode zelf, maar ook het proces van het opstellen van een gedragscode kan volgens respondenten winstpunten meebrengen. Zo wordt het opstellen van een gedragscode als waardevol gezien, omdat dit er toe leidt dat de bij de afhandeling betrokken partijen met elkaar in gesprek gaan en dit overleg er aan kan bijdragen dat partijen elkaar leren begrijpen:

'Nou ja, wat het maken van een gedragscode, daar gaat aan vooraf dat je met elkaar in overleg treedt. Daar zit misschien de meeste winst in. Elkaar leren begrijpen.'20

'En ja, het [opstellen van een gedragscode] is eigenlijk het verkrijgen van gemeenschappelijk inzicht over wat er eigenlijk speelt. En dan komt vanzelf het inzicht mee wat je daaraan zou kunnen doen.'21

Ook zijn als winstpunten aangevoerd dat het opstellen van een gedragscode ertoe kan leiden dat de sfeer tussen partijen verbetert en dat de thematiek van beroepsziekteclaims op de agenda wordt gehouden:

'En dat, wat je ook wel bij de GBL ziet, is dat dat [het opstellen van een gedragscode] inderdaad leidt tot een andere verstandhouding en wellicht iets makkelijkere manier van omgang met elkaar. ${ }^{22}$

'Ik vind het überhaupt al goed dat dit [de afhandeling van beroepsziekteclaims] als probleem wordt onderkend en dat er aandacht aan wordt besteed. Dat is natuurlijk al gewoon belangrijk.' ${ }^{23}$

\subsubsection{Voormaarden en nadelen}

Een gedragscode biedt volgens respondenten niet zonder meer een oplossing. Voor het slagen van een gedragscode zijn immers verschillende voorwaarden genoemd. In dit verband is onder andere aangevoerd dat zowel voor het opstellen van een gedragscode als voor de inhoud van de gedragscode voldoende draagvlak aanwezig dient te zijn. Zo is opgemerkt dat partijen positief 
dienen te staan tegenover de mogelijkheid van een gedragscode en bereid dienen te zijn om bij te dragen aan het ontwerpen hiervan:

'Als de wens is om een gedragscode te maken, dan ligt het in de lijn om het op deze manier te doen.'24

Eveneens moeten partijen bereid zijn om de wijze waarop zij handelen tijdens de afhandeling van een beroepsziekteclaim aan de gedragscode aan te passen:

'Ja, een gedragscode is soft lam. Wat je daarin opschrijft moet eigenlijk toch wel voldoende draagvlak hebben bij partijen. Dus, ja, of een gedragscode iets zou kunnen daar ga ik niet over. In theorie wel, maar dan moet er binnen partijen draagvlak zijn om dingen anders te gaan doen. Een gedragscode is eigenlijk gewoon een set afspraken over hoe je dingen beter kunt doen. ${ }^{25}$

Behalve voorwaarden is ook een aantal nadelen van de gedragscode genoemd. Zo is door een aantal respondenten (expliciet) benadrukt dat een gedragscode niet alle genoemde knelpunten kan oplossen. In dit verband is onder andere gewezen op 'de grote problemen', waaronder niet alleen de moeilijk te doorgronden jurisprudentie van de Hoge Raad lijkt te zijn verstaan, maar ook het vaststellen van de blootstelling en de causaliteit.

Een ander nadeel van een gedragscode betreft volgens respondenten dat naar verwachting niet alle betrokken partijen zich hieraan zullen binden, hetgeen de effectiviteit van een gedragscode in de weg kan komen te staan:

'Waarbij ik wel moet opmerken dat dit soort dingen [afspraken in een gedragscode] vervelend zijn, omdat de enige partij die eraan is gebonden, is de verzekeraar. De belangenbehartiger en zeker de advocaat mag zich natuurlijk niet binden aan iets dat zijn cliënt kan beperken. En het vervelende is wat je dan ziet, dat hebben we in eerdere pilots met beroepsziekten ook gezien, dat als er aan het einde van de rit niet uitkomt wat ze willen horen, er altijd nog de mogelijkheid openstaat van een $o p t-o u t .{ }^{26}$

Volgens anderen vormt het zich niet binden door een deel van de betrokken partijen daarentegen geen probleem, omdat ook zonder het vooraf ondertekenen door betrokken partijen een gedragscode voldoende effect kan sorteren. In die zin, dat betrokken partijen zich in de praktijk aan de gedragscode zullen houden of dat er van een gedragscode toch een normerend effect uitgaat:

'Met de GBL is dat [dat partijen zich in de praktijk aan de GBL houden] volgens mij wel gelukt. Daarom heeft het mij bij de GBL ook steeds zo gestoord, dat onnodige druk werd gelegd op elkaar om zich eraan te binden. In plaats van te zeggen dat is zo en laten we nu eens kijken: wat komt er nu van terecht? Ik denk dat de GBL prima werkt. Sterker nog: ik denk dat, doordat er dermate goed overleg is, dat de GBL niet negatief benut wordt door advocaten. Want ook dat zou je je nog kunnen voorstellen. Als jij voor een slachtoffer optreedt en de verzekeraar waartegen je handelt, die weet wederom niet binnen de zichzelf opgelegde termijn te antwoorden. Als je vervelend wilt zijn, dan kun je klacht op klacht indienen. Ik denk dat de grote winst is dat dat niet gebeurt. ${ }^{27}$

\section{Slot}

Met als doel om te bezien of voldoende aanknopingspunten bestaan om te gaan werken aan de totstandkoming van een Gedragscode Afhandeling Beroepsziekteclaims, is in het kader van het project GAB een inventariserend onderzoek verricht naar de ervaren problemen bij de afhandeling van beroepsziekteclaims en naar de kansen van een gedragscode als oplossingsrichting. Gebleken en bevestigd is dat de afhandeling van beroepsziekteclaims in de praktijk als (zeer) problematisch wordt ervaren; de afhandeling duurt (te) lang, kost (te) veel en is (te) belastend voor betrokken partijen. Over de mogelijkheid van een gedragscode als oplossingsrichting voor deze problematiek heeft het - veruit - overgrote deel van de respondenten zich positief uitgelaten. Ook hebben zij zich bereid getoond te willen bijdragen aan het opstellen van de gedragscode. Op basis van de bevindingen van het inventariserende onderzoek is dan ook geconcludeerd dat voldoende aanknopingspunten bestaan om door te gaan naar de tweede fase van het project $G A B$, de fase waarin door een breed samengestelde werkgroep en stuurgroep zal worden getracht handen en voeten te geven aan de gedragscode. Dat proces is inmiddels gestart. 